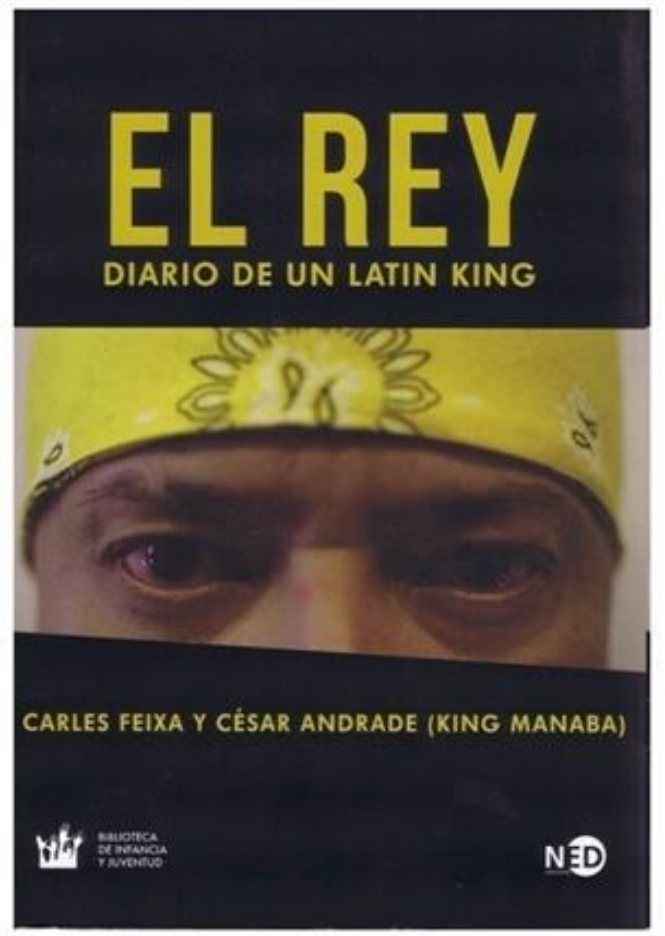

\title{
En busqueda de futuro. A propósito de El Rey. Diario de un Latin King
}

Joan Ramon Saura-Aranda

Universitat Pompeu Fabra, España

Feixa, C., \& Andrade, C. (2020). El Rey. Diario de un Latin King. NED. ISBN: 978-8416737-85-7. Biblioteca de Infancia y Juventud. Serie Transgang 1.512 pp. https://nedediciones.com/ficha.aspx? $\operatorname{cod}=2041$ https://dx.doi.org/10.116oo/rlcsnj.20.1.Eo7

En palabras de Nuccio Ordine, la definición de un clásico, sea en la expresión artística que sea, responde al aporte que hace «sobre el arte de vivir y sobre las formas de resistir la dictadura del utilitarismo y el beneficio» (Ordine, 2017). Cada vez que se leen, los clásicos, te aportan algo, permitiendo reinterpretar los signos de los tiempos en que se vive. He hecho referencia a los clásicos, porque Carles Feixa, en mi opinión, está en camino de convertirse en un clásico en temas de juventud, camino que empezó a partir de la publicación en 1998 del libro De jóvenes, bandas y 
tribus, obra que va por la quinta edición, además de otros libros y artículos han marcado impronta en la llamada cuestión juvenil, tan de actualidad hoy y siempre.

En este sentido, contribuye a ello, sin duda, su último libro, El Rey. Diario de un Latin King, escrito a cuatro manos con Cesar Andrade (King Manaba). El libro tiene, a mi parecer, antecedentes en dos de las historias de vida que cierran el citado De jóvenes, bandas y tribus (Felix, soy un mutante y Pablo, si soy o no soy punk), a la vez que también se intuye una cierta aura de Los Barjots, de Jean Monod (1968/2002). A tener presente también la reciente traducción de otro clásico, hasta ahora no editado en castellano, como es la obra de Frederic M. Thrasher La banda (1927/2021), realizada conjuntamente con María Oliver.

Pero volviendo a El Rey, que es la obra que nos ocupa, diría que en su recorrido presenta mayoritariamente aspectos de comedia, aunque también con items de tragedia, ya que tal y como apunta Josep M. Micó en su prólogo de la Comedia de Dante (este año setecientos aniversario de la muerte del insigne florentino), «en oposición a la tragedia, la comedia comienza mal, pero acaba bien» (Mico, en Alighieri, 2018). Así, El Rey empieza en un infierno y termina en lo que, tal vez pueda devenir paraíso, entendiendo la acepción de paraíso, en este caso, no como una situación idílica sino como una situación que permite empezar a vislumbrar futuro. Al mismo tiempo, el lenguaje de la obra rige una cotidianidad muy propia de la calle, emanando un sentido de censura moral hacia un sistema social injusto en muchas ocasiones.

Apunto lo de tragedia porque, aunque la historia de vida de Cesar, aka King Manaba, se podría corresponder más a una comedia, en muchos pasajes tanto él como muchos/as de sus compañeros/as se convierten en chivos expiatorios de unas sociedades y sistemas donde la condición juvenil va asociada a situaciones extremas. Al respecto son harto interesantes las aportaciones que hacen Jordi Balló y Xavier Pérez en su libro El mundo un escenario. Shakespeare el guionista invisible, que permite concretar unos escenarios de personajes y ambientes donde vida y fatum hacen viaje: futuros ausentes a la vez que secuestrados, violencia, ambientes opresivos y asfixiantes, pobreza, etc. Así, al contrario de lo que sucede en la tragedia griega, en este caso acudiría más a la shakespeariana, donde se encarna lo oscuro de lo humano (Balló \& Pérez, 2015).

En estos aconteceres, el hecho biográfico adquiere capital importancia, enfatizando Feixa (siguiendo a Franco Ferrarotti) que «el objetivo final del libro es leer una sociedad a través de una biografía», por lo que se estaría ante «un instrumento de reparación de memorias de vidas dañadas por toda clase de razones... pudiendo convertirse, además de en un relato, en un medio de esclarecimiento histórico/moral, vaciando la leyenda del personaje de ciertas 
hostilidades que pudo/ha generado en su vida, al tiempo que proponiendo un contexto más ajustado a los hechos» (Caballé, 2018). Se trata de acercarse a ellos, los hechos, no tanto para justificar conductas sino para matizarlas acudiendo al contexto vital e histórico (mediante los cronotopos). Salvando las distancias, y permítaseme la licencia, estaríamos ante una especie de poema sacro, como al que hace mención Dante en el canto XXV del Paraíso de la Comedia y que dice: «Si alguna vez este poema sacro... vence la crueldad que me ha excluido/del redil donde fui feliz cordero/odiado por los lobos que hoy lo hostigan» (Aliguieri, 2018). En el caso de King Manaba, le permitiría apropiarse de su vida, desde un posicionamiento público en pos de una inclusión social que podría actuar como referente para otros/as jóvenes en su misma situación.

Poniendo el acento en la condición relacional entre sociedad y vida, que dimana de El Rey, quisiera recordar las palabras de Rossana Reguillo en el prólogo del libro de José M. Valenzuela Vida de barro duro cuando escribe: «las geografías movedizas de la vida de millones de jóvenes en Latinoamérica, nos ponen en contacto con el olor de la pobreza de los cinturones de miseria y con el olor de la adrenalina de los cuerpos perseguidos por la policía o por los escuadrones de la muerte» (Reguillo, en Valenzuela, 1997). Significativo el título del libro de Valenzuela, pues el barro en su capacidad de ductilidad, a la vez que insuflándole un aliento adecuado, contiene en su halo los atributos inherentes a la vida. Cuando el barro está reseco y duro, los alientos creadores de condiciones de vida son inexistentes, convirtiéndolo en un material quebradizo y por tanto rechazable, reflejándose en esta metáfora del barro la vida de muchos/as jóvenes de determinados lugares. A tener presente, la realidad que envuelve la condición juvenil en países como Ecuador, El Salvador, Colombia, México... donde las personas son chunchurrias y siempre están a punto de quebrar, quiñar y/o a desprender olor a formol y viajar, en los argots de banda que reseña Alonso Salazar en No nacimos pa' semilla (Salazar, 1998). Resonarían en nuestros oídos los acordes y estrofas de la canción de Pablo Guerrero A Cantaros que dicen: «Estamos amasados con libertad muchacha / pero, ¿quién nos ata?/ pero, ¿quién nos ata?/ Ten tu barro dispuesto/ elegido tu sitio/ preparada tu marcha/ Hay que doler de la vida hasta creer» (Guerrero, 1972).

Otro tema que considero primordial en la obra sería el de la mediación, que vendría al ser «la lucha contra <el hybris», contra la desmesura, pues la libertad colectiva sólo puede funcionar si existe la mediación» (Argullol, 2020), a la vez que ésta es «ley y comprensión, autoridad y libertad, poder e inteligencia» (RodríguezAdrados, 1966). Hago referencia expresa al tema de la mediación, porque ésta late en buena parte del relato, y también porque debería tenerse muy en cuenta como actitud, en pro de la reconducción, de muchas de las problemáticas que conforman 
las relaciones entre colectivos juveniles y su entorno, siendo desde el entendimiento desde donde deberá articularse cualquier proceso desestigmatizador a la vez que socializador. Aquí, y recurriendo otra vez a la Comedia de Dante, y en concreto al Canto XXVIII del Purgatorio, Manaba a indicación de su guía Feixa, bebe de las aguas de los ríos Leteo y Eunoe (el primero elimina las heridas ocasionadas por los malos recuerdos, el segundo invita a hacer el bien), mientras sopla Eolo un viento liberador. En El Rey, se pone de manifiesto cómo mediante dichos procesos, y a pesar de los muchos condicionantes contextuales, es posible que muchos/as jóvenes, sobre todo recién llegados/as aquí no tengan que transitar por infiernos, haciendo posible que aquella sentencia que se lee en el Canto III del Infierno de la Comedia, que dice «Dejen toda esperanza los que aquí entren», sea evitable.

Incidiría también en la cuestión religiosa, pues más allá de la intervención de algún sacerdote, esta se hace presente mediante expresiones y simbologías. De esta manera, y siguiendo a Lluís Duch cuando escribe que «para el ser humano no hay posibilidad extracultural» (Duch, 2012), en ciertos pasajes se asiste a una clara relación entre cultura y religión, al articularse culturalmente lo estructural (religión) con la historia (biografía). Esto se hace presente, en considerar que los conceptos de finitud y contingencia son inherentes a la naturaleza humana per se, poniéndose de manifiesto sobremanera en la trayectoria vital de Manaba. A modo de ejemplos: en la acepción de Nación, interpreto que tienen un peso específico la memoria y la tradición de allá, aunque su encaje ha de realizarse aquí en el seno de una sociedad con fuertes procesos de secularización y destradicionalización; determinadas expresiones que suenan más como imprecaciones; la Virgen de Guadalupe, el rosario de colores, etc., actúan como lugares de la memoria remitiéndonos a ausencias hechas presencias. Al respecto Clifford Geertz apunta que «society is subordínate to culture» (Geertz, 1987), o sea que las relaciones que adopta el ser humano con su entorno pueden dar lugar a un nuevo concepto de religión (Duch, 2012).

Quiero terminar con unas frases del escritor griego Theodor Kallifatides, que emigró a Suecia, el sentido de las cuales tendría que impactar en la conciencia de Europa y en la de todos aquellos países receptores de inmigración. Las frases que hacen al caso serían: «Yo no solo era un inmigrante, era un griego... Europa entera nos vilipendiaba. Éramos haraganes, ladrones, pensionistas de nacimiento... Me acordé de los afiches de Goebbels, en los que se representaba a los griegos como monos... Europa calculaba cuanto le debíamos, mientras en el Egeo los refugiados arriesgaban su vida... Se habían abandonado a su destino...» (Kallifatides, 2019). Podría sustituirse el topónimo griegos por el de ecuatorianos, colombianos, magrebíes, subsaharianos, etc... y Egeo por el de otras geografías, en donde la vida 
en palabras de Kostakis desprende «hedor a humanidad» (Ibid). Pienso que estas frases podrían enmarcar el espíritu de la inmigración en general, y la de los/las jóvenes en particular, del que Manaba sería un ejemplo, no bajo pretexto de justificar procederes conductuales, sino para obligarnos a una reflexión que sea tránsito hacia horizontes de futuro. La respuesta, formateando un tanto a Bob Dylan que este año ha cumplido ochenta años, me gustaría que no «estuviera en el viento».

I've been set free and I've been bound To the memories of yesterday's clouds

I've been set free and I've been bound

And now I'm set free

I'm set free to find a new illusion.

Lou Reed (1998)

\section{Referencias}

Alighieri, D. (2018). Comedia. Prólogo, comentarios y traducción a cargo de Micó, José Maria. Acantilado.

Argullol, R. (2020). La Contra. La Vanguardia.

Balló, J. \& Pérez, X. (2015). El món un escenari. Shakeaspeare: el guionista invisible.

Anagrama.

Caballé, A. (2018). Escribir las vidas ajenas. Babelia.

Duch, L1. (2012). La religión en el siglo XXI. Siruela.

Feixa, C. (1998). De jóvenes, bandas y tribus. Ariel.

Geertz, C. (1987). La interpretación de las culturas. Gedisa.

Guerrero, P. (1972). A Cántaros. Acción.

Kallifatides, Th. (2019). Otra vida por vivir. Galaxia Gutenberg.

Monod, J. (1968/2002). Los Barjots. Ensayo de etnología de bandas de jóvenes. Ariel.

Ordine, N. (2017). Classics per a la vida. Una petita biblioteca ideal. Quaderns Crema.

Reed, L. (1998). The Velvet Underground, Editorial Fundamentos.

Rodríguez-Adrados, F. (1966). Ilustración y política en la Grecia clásica. Occidente.

Salazar, A. (1998). No nacimos pa' semilla. Cinep.

Thrasher, F. (1927/2021). La Banda. Un estudio de 1313 bandas en Chicago. NED. Edición a cargo de Feixa, C., \& Oliver, M.

Valenzuela, J. M. (1997). Vida de barro duro. Universidad de Guadalajara, El Colegio de la Frontera Norte. Prólogo de Rossana Reguillo. 